\title{
Çiftçilerin Tarım Sigortası Yaptırma İstekliliği: Konya İli Ilgın İlçesi Örneği
}

\author{
Emine İKİKAT TÜMER ${ }^{1}$ (D), Hasan Burak AĞIR ${ }^{2}$ (D) Zeliha USLU 3 (D) \\ 1,2Kahramanmaraş Sütçü İmam Üniversitesi, Ziraat Fakültesi, Tarım Ekonomisi Bölümü, Kahramanmaraş \\ ${ }^{1}$ https://orcid.org/0000-0001-6336-3026, ${ }^{2}$ https://orcid.org/0000-0003-4275-9819, ${ }^{3}$ https://orcid.org/0000-0002-4730-9529 \\ $\bowtie$ : etumer@ksu.edu.tr
}

\section{ÖZET}

Tarım sektörü; doğal, sosyal ve ekonomik risk ve belirsizliklerden en çok etkilenen sektördür. Bu risk ve belirsizlikleri en aza indirmenin en kolay yollarından birisi de tarım sigortalarıdır. Tarım sigortaları çiftçinin kayıplarını tazmin etmenin yanı sıra işletmelerin varlığını sürdürmesini de sağlamaktadır. Araştırmada çiftçilerin bitkisel ürün sigortası yaptırmalarında etkili olan faktörlerin belirlenmesi amaçlanmıştır. Araştırma Konya ili Ilgın ilçesinde yürütülmüştür. Araştırmanın materyalini 95 üretici ile yüz yüze yapılan anketlerden elde edilen veriler oluşturmaktadır. Elde edilen verilerin değerlendirilmesinde tanımlayıcı istatistikler ve Binomial probit modeli kullanılmıştır. Analiz sonucunda çiftçilerin bitkisel üretim tecrübesi, ailedeki birey sayısı, çiftçinin eğitimi, bitkisel üretim geliri ve bitkisel ürün sigortaları kapsamının genişletilmesi isteği ile pozitif yönlü, işletme dışı yatırımla ise negatif yönlü ilişki olduğu tespit edilmiştir.

\section{Araştırma Makalesi}

Makale Tarihçesi

Geliş Tarihi : 16.01 .2019

Kabul Tarihi : 14.03 .2019

Anahtar Kelimeler

Bitkisel üretim

Bitkisel ürün sigortası

Karar verme

Binomial Probit modeli

\section{Farmers' Crop Insurance Purchase Willingness: The Case of Ilgin Province in Konya}

\begin{abstract}
Agricultural sector is the most affected sector from natural, social and economic risks and uncertainties. One of the easiest ways to reduce these risks and uncertainties is to have the agricultural insurance. Agricultural insurance is not only compensating farmers for their production losses but also maintain the existence of enterprises.

The purpose of the research is to determine the factors affecting producers' purchase decision of agricultural insurance. The research was conducted in Ilgin Province of Konya. The material of the research is obtained from 95 producers' face to face interviews. Descriptive statistics and Binomial probit model were used for evaluation of the data. The results indicated that while there was a positive relation with producer's experience in plant production, number of family members, producer's education, plant production income and request to expand the scope of agricultural insurance, there was a negative relation with non-operating investment.
\end{abstract}

\section{Research Article}

$\begin{array}{ll}\text { Article History } & \\ \text { Received } & : 16.01 .2019 \\ \text { Accepted } & : 14.03 .2019\end{array}$

\section{Keywords}

Crops

Crop insurance

Decision making

Binomial Probit model

To Cite : İkikat Tümer E, Ağır HB, Uslu Z 2019. Çiftçilerin Tarım Sigortası Yaptırma İstekliliğ̣i: Konya İli Ilgın İlçesi Örneği. KSÜ Tarım ve Doğa Derg 22(4): 571-576. DOI: 10.18016/ksutarimdoga.vi.513366.

\section{GİRIŞ}

Tüm sektörler içerisinde tarım, çiftçilerin gelirlerinde dengesizliklere neden olan doğal sosyal ve ekonomik risklerle daha fazla karşı karşıyadır (Çukur ve Saner, 2008; İkikat Tümer, 2011a; İkikat Tümer, 2011b; Karahan Uysal ve ark., 2014; Terin ve Aksoy, 2015). $\mathrm{Bu}$ risklerden sadece çiftçiler değil aynı zamanda tarımsal girdi üreten tedarikçilerden son tüketiciye kadar zincirin tüm halkaları etkilenmektedir (Hassanpour ve ark., 2013; Zulfiqar ve ark., 2016; Farzaneh ve ark., 2017). Tarım sektöründe çok, çeşitli ve yaygin olan bu risklerin üstesinden gelmenin yollarından birisi de tarım sigortalarıdır (Binici ve ark., 2003; İkikat Tümer, 2004). Tarım sigortaları çiftçilerin kayıplarını tazmin etmenin yanı sıra işletmelerin varlığını sürdürmelerini de garanti etmektedir (Akçaöz ve ark., 2006). Tarımsal üretimde çiftçilerin karşılaştığı riskler sigorta organizasyonları vasitasiyla sigortaciya transfer edilmektedir. $\mathrm{Bu}$ transferde sigortacıya riskleri üstlenmesi karşılığ olarak prim ödenmektedir. Prim miktarı riskin şiddeti, oluş sıklığı ve meydana getirmiş olduğu hasarlara bağlı olarak değişmektedir (Saner, 1999).

Dünyada son yıllarda çiftçilerin tarım sigortası 
yaptırma karar ve istekliliğini araştıran birçok çalışma yapılmıştır. Bunlar arasında Avrupa Birliği (Sherrick, 2004), Çin (Xiu ve ark., 2012), Kuzey İngiltere (Liesivaara ve Myra, 2014), Pakistan (Ghazanfar ve ark., 2015) sayılabilir. Bu çalışmalarda çiftçilerin yaşı, geliri, prim miktarı tarım sigortası yaptırma istekliliğinde önemli değişkenler arasında yer almaktadır.

Türkiye'de 14.06.2005 yılında 5363 Sayılı Tarım Sigortaları Kanununun kabulü ve \%50 prim desteğinin devlet tarafından sağlanması ile tarım sigortalarının gelişmesi ivme kazanmıştır. Ülkede 2011-2016 yılları içerisinde sigorta bedeli, prim üretimi ve poliçe sayısı yaklaşık 3 kat büyümüştür. 2016-2017 yılları arasında toplam poliçe sayısında \%6, prim üretiminde $\% 19$, sigorta bedelinde $\% 21$, sigortalı alanda $\% 5$, sigortalı hayvan sayısında \%35 ve sera sayısında \%5 oranında artış meydana gelmiştir (TARSİM, 2017).

Tarım sigortaları içerisinde bitkisel ürün sigortalarının sigorta bedeli içerisindeki payı Türkiye'de \%65.8, Konya'da ise \%6.7'dir. Bu oranla Konya ili 2. sırada yer almaktadır. Bitkisel ürün sigortalarının prim üretimi içerisindeki payı Türkiye'de \%75.0, Konya'da ise \%2.9 olup bu oranla Konya ili 6. sırada yer almaktadır. Bitkisel ürün sigortaları poliçe sayısında ise Türkiye'nin \%94.6'sını oluşturmakta ve Konya ili \%8.2 pay ile 3 . sırada yer almaktadır (TARSIM 2017).

Tarım sigortaları içerisinde sigorta bedeli, prim üretimi ve poliçe sayısında Konya ili ilk sıralarda yer almaktadır. Bu çalışmada Konya ili Ilgın ilçesinde çiftçilerin bitkisel ürün sigortası yaptırmalarını etkileyen faktörlerin belirlenmesi amaçlanmıştır. Ayrıca bitkisel ürün sigortası yaptıran çiftçi sayısının artırılması ile ilgilenen özel şirket, kamu kurum ve kuruluşlarına rehberlik edecek bir kaynak oluşturması da hedeflenmektedir.

\section{MATERYAL ve YÖNTEM}

Konya ili Ilgın ilçesi Tarım ve Orman Bakanlığı İlçe Müdürlüğü çiftçi kayıt sistemine kayıtlı işletme sayısı dikkate alınarak anket sayısı belirlenmiştir. İlçede yapılacak anket sayısının belirlenmesinde Oransal Örnekleme yöntemi kullanılmıştır (Miran, 2013). Bu yönteme göre anket sayısının belirlenmede aşağıdaki formül kullanılmıştır.

$$
n=\frac{N * p^{*}(1-p)}{(N-1) * \sigma_{p}^{2}+p *(1-p)}=\frac{5453 * 0.5 * 0.5}{5452 * 0,0026+0.5 * 0.5} \cong 95
$$

$\sigma_{p}^{2}=\left(\frac{r}{Z_{\alpha / 2}}\right)=\left(\frac{0.10}{1.96}\right)^{2}=0.0026$

Formülde; n: Örnek büyüklüğü, N: Popülasyondaki işletme sayısı, $\sigma_{p}^{2}$ : Oranın varyansı, r:Ortalamadan izin verilen hata payı $(\% 10), \mathrm{Z}_{\alpha / 2}: \mathrm{z}$ cetvel değeri, $\mathrm{p}$ : Populasyon içerisinde çiftçilerin bitkisel ürün sigortası yaptırma olasılığını göstermektedir. Burada \%95 güven aralığında $(\mathrm{z}=1.96)$ ve ortalamadan $\% 10$ sapma ile anket yapılacak çiftçi sayısı 95 olarak belirlenmiştir.

\section{Binomial Probit Modeli}

Bağımlı değişken bir olayın olma/olmama durumunu ifade eden nitel bir değişken ise Sinırlı Bağımlı Değişken Regresyon Modelleri kullanılmaktadır (Yavuz 2001; Gujarati 2006). Bağımlı değişkenin iki durumu ifade etmesi halinde Doğrusal Olasılık Modeli, Logit Modeli ve Probit Modeli kullanılmaktadır. Probit ve Logit modellerinde tahmin edilen olasılıklar 0-1 aralığına düşmekle birlikte bu modeller birbirine benzerdir (Gujarati 2006; Sarımeşeli 2000). Bu çalışmada çiftçilerin bitkisel ürün sigortası yaptırma " 1 ” ve yaptırmama " 0 " durumlarını etkileyen faktörleri belirlemek için Binomial Probit modeli kullanılmıştır.

Probit modelde, çiftçilerin tarım sigortası yaptırma ve yaptırmama durumu gözlenmeyen bir fayda indeksine (Ii) bağlı olduğu varsayılmaktadır. Fayda indeksi, bağıımsız değişkenlere bağlı olup indeksin büyüklüğü arttıkça olayın olma olasılığı artmaktadır.

$I_{i}=B_{1}+B_{2} X_{i}$

Burada; $\mathrm{I}_{\mathrm{i}}: \quad$ Fayda indeksini, $\quad B_{1}:$ Sabit değeri, $B_{2}$ :bağımsız değişkene ait katsayıyı, $X_{i}$ ise bağımsız değişkeni ifade etmektedir (Gujarati 1995, Akkaya ve Pazarlıŏlu 1998 ).

Çalışmada çiftçilerin bitkisel ürün sigortası yaptırma kararlarını etkileyen faktörleri belirlemek için tahmin edilen modelde bitkisel üretim tecrübesi, ailedeki birey sayısı, çiftçinin eğitimi, bitkisel üretim geliri, kooperatife üyelik, işletme dışı yatırım, köye yenilikleri getirme durumu, bitkisel ürün sigortaları kapsamının genişletilmesi isteği bağımsız değişkenler olarak kullanılmıştır. Bu değişkenlerin seçiminde önceki çalışmaların sonuçları ve değişkenler arası korelasyon dikkate alınmıştır.

\section{ARAŞTIRMA BULGULARI}

Araştırma bölgesindeki çiftçilerin yaşı ortalama 46.23 yıl, ailelerindeki birey sayısı ortalama 4.54 kişi, tarımda çalışan aile birey sayısı ortalama 2.38 kişi ve bitkisel üretim tecrübesi ortalama 21.49 yll olarak hesaplanmıştır. Çiftçilerin bitkisel üretimden elde ettikleri yıllık gelir ortalama $65694.74 \mathrm{TL} / \mathrm{yll}$ ve toplam arazi varlığ belirlenmiştir (Çizelge 1). Ankete katılan çiftçilerin \%37.90'u lise mezunu olup, \%61.05'inin sosyal güvencesi bulunmakta ve \%40.00’ı tarım dışı işte çalışmaktadır.

Çiftçilerin \%29.50'sinin işletme dışı yatırımı olduğu, 
\%92.63’ünün herhangi bir kooperatife üye oldukları ve \%42.11'i tarımla ilgili kuruluşlarla orta sıklıkta görüştükleri tespit edilmiştir. Araştırma bölgesindeki çiftçilerin \%49.47'si kuraklıkla sıklıkla karşılaştıklarını ifade etmişlerdir. Ankete katılanların $\% \% 88.42$ 'si şans oyunu oynamamaktadırlar. Çiftçilerin \%84.21'inin sözleşmeli üretim yaptığı, \%80’inin bitkisel ürün sigortasının tanımını bildiği ve \%77.89'unun bitkisel ürün sigortası yaptırdığı tespit edilmiştir. Bitkisel ürün sigortası yaptıran çiftçilerin $\% 73.68$ 'i tekrar sigorta yaptırmak istediklerini belirtmişlerdir. Anket katılanların \%52.60'ı köye yenilikleri kendilerinin getirdiklerini ifade etmişlerdir (Çizelge 2).

Çizelge 1. Çiftçilerin sosyo-demografik özellikleri

\begin{tabular}{lrrrr}
\hline & Minimum & Maksimum & Ortalama & Std. Ss. \\
\hline Yas & 20 & 67 & 46.23 & 9.28 \\
Ailedeki birey sayısı & 2 & 9 & 4.54 & 1.54 \\
Tarımda çalışan birey sayısı & 1 & 6 & 2.38 & 1.12 \\
Bitkisel üretim tecrübesi & 3 & 45 & 21.49 & 9.90 \\
Bitkisel üretimden elde edilen gelir (TL/Yıl) & 8000 & 250000 & 65694.74 & 48458.16 \\
Toplam arazi varlığı & 16 & 865 & 207.89 & 131.86 \\
\hline
\end{tabular}

Cizelge 2. Çiftçilere ait özellikler

\begin{tabular}{|c|c|c|c|c|c|c|c|}
\hline & & $\mathrm{N}$ & $\%$ & & & $\mathrm{~N}$ & $\%$ \\
\hline \multirow{4}{*}{ Eğitim } & İlkokul & 26 & 27.37 & \multirow{4}{*}{ Karşılaşılan afet } & dolu & 26 & 27.37 \\
\hline & Ortaokul & 33 & 34.74 & & don & 22 & 23.16 \\
\hline & Lise+ & 36 & 37.90 & & kuraklık & 47 & 49.47 \\
\hline & Total & 95 & 100.00 & & Total & 95 & 100.00 \\
\hline \multirow{3}{*}{ Sosyal güvence } & Yok & 37 & 38.95 & \multirow{3}{*}{ Şans oyunu oynama } & Hayır & 84 & 88.42 \\
\hline & Var & 58 & 61.05 & & Evet & 11 & 11.58 \\
\hline & Total & 95 & 100.00 & & Total & 95 & 100.00 \\
\hline \multirow{3}{*}{ Tarım dışı işte çalışma durumu } & Çalışmıyor & 57 & 60.00 & \multirow{3}{*}{$\begin{array}{l}\text { Sözleşmeli üretim } \\
\text { yapma durumu }\end{array}$} & Hayır & 15 & 15.79 \\
\hline & Çalışıyor & 38 & 40.00 & & Evet & 80 & 84.21 \\
\hline & Total & 95 & 100.00 & & Total & 95 & 100.00 \\
\hline \multirow{3}{*}{ İşletme dışı yatırım olma durumu } & Olmayan & 67 & 70.50 & \multirow{3}{*}{$\begin{array}{l}\text { Bitkisel ürün } \\
\text { sigortası yaptırma }\end{array}$} & Hayır & 21 & 22.11 \\
\hline & Olan & 28 & 29.50 & & Evet & 74 & 77.89 \\
\hline & Total & 95 & 100.00 & & Total & 95 & 100.00 \\
\hline \multirow{3}{*}{ Kooperatife üyelik } & Olmayan & 7 & 7.37 & \multirow{3}{*}{$\begin{array}{l}\text { Tekrar bitkisel ürün } \\
\text { sigortası yaptırma } \\
\text { isteği }\end{array}$} & Hayır & 4 & 4.21 \\
\hline & Olan & 88 & 92.63 & & Evet & 70 & 73.68 \\
\hline & Total & 95 & 100.00 & & Total & 74 & 77.89 \\
\hline \multirow{3}{*}{$\begin{array}{l}\text { Tarımla ilgili kuruluşlarla } \\
\text { görüşme sıklığ }\end{array}$} & $\mathrm{Az}$ & 36 & 37.89 & \multirow{3}{*}{$\begin{array}{l}\text { Köye } \\
\text { getirme }\end{array}$} & Hayır & 45 & 47.40 \\
\hline & Orta & 40 & 42.11 & & Evet & 50 & 52.60 \\
\hline & Sik & 19 & 20.00 & & Total & 95 & 100.0 \\
\hline
\end{tabular}

Çiftçilerin bitkisel ürün sigortası yaptırmalarını $(\mathrm{Y}=1)$ etkileyen çiftçi ve işletme özellikleri ile bu faktörlerin marjinal etkileri Binomial Probit Model ile tahmin edilmiştir. Binomial Probit modelinin LR $\chi^{2(8)}$ değeri $(\mathrm{p}=0.000)$, istatistiksel olarak modelin kullanılabilir olduğunu göstermektedir (Çizelge 3). Modelde yalnızca istatistiki açıdan önemli olan değişkenler üzerinde durulmuştur.

Çiftçilerin bitkisel ürün sigortası yaptırma durumu ile bitkisel ürün üretim tecrübeleri arasında pozitif yönlü bir ilişki mevcuttur. Çiftçilerin bitkisel üretim yaptıkları yıl sayısı arttıkça bitkisel ürün sigortası yaptırma isteği \%1.16 artmaktadır. Bir başka ifadeyle tecrübeli çiftçiler önceki yıllarla mevcut yılı karşılaştırabilmekte ve son yıllarda hafif, orta ve şiddetli kuraklığın görüldüğü araştırma bölgesinde meteorolojik riskleri transfer etmeyi istemektedirler.
$\mathrm{Bu}$ durum istatistiki açıdan önemlidir $(\mathrm{P} \leq 0.05)$ (Çizelge 3). Kuzey İran (Farzaneh ve ark., 2017), Antalya (Sayın ve ark., 2014), Kırklareli ve Edirne (Aydın ve ark., 2016) ve Uşak (Naseri ve Saner, 2017) illerinde yapılan çalışmalarda da deneyimli çiftçilerin bitkisel ürün sigortası yaptırmaya daha istekli oldukları tespit edilmiştir.

Bitkisel ürün sigortası yaptırma ile çiftçinin bakmakla yükümlü olduğu birey sayısı arasında pozitif yönlü bir ilişki mevcuttur. Çiftçinin ailesinde 5 kişi ve daha fazla birey olması durumunda çiftçilerin bitkisel ürün sigortası yaptırması \%18.32 artmaktadır. Bir başka ifade ile çiftçiler ailelerinde bakmakla yükümlü oldukları birey sayısı arttıkça elde edecekleri ürünün kalite veya miktar kaybından kaynaklanacak gelir azalmasina katlanmak istememektedirler. Bu durum istatistiki açıdan önemlidir $(\mathrm{P} \leq 0.05)$ (Çizelge 3$)$. 
Çizelge 3. Binomial Probit modelinin tahmini parametre değerleri ve modeldeki değişkenlerin marjinal etkileri

\begin{tabular}{|c|c|c|c|c|}
\hline & Katsayı & & \multicolumn{2}{|c|}{ Marjinal etki } \\
\hline Sabit & $\begin{array}{l}-2.7278 \\
(1.4944)\end{array}$ & * & & \\
\hline Bitkisel üretim tecrübesi & $\begin{array}{l}0.0652 \\
(0.0300)\end{array}$ & $* *$ & $\begin{array}{l}0.0116 \\
(0.0048)\end{array}$ & $* *$ \\
\hline Birey sayısı (5 kişi ve daha fazla:1, Diğer:0 & $\begin{array}{l}0.8811 \\
(0.4131) \\
\end{array}$ & $* *$ & $\begin{array}{l}0.1832 \\
(0.0932)\end{array}$ & $* *$ \\
\hline Ĕgitim & $\begin{array}{l}0.4581 \\
(0.2624)\end{array}$ & * & $\begin{array}{l}0.0811 \\
(0.0429)\end{array}$ & * \\
\hline Bitkisel üretim geliri (1000 TL) & $\begin{array}{l}0.0219 \\
(0.0070)\end{array}$ & $* * *$ & $\begin{array}{l}0.0039 \\
(0.0011)\end{array}$ & $* * *$ \\
\hline Kooperatife üyelik & $\begin{array}{l}-0.9878 \\
(0.8569)\end{array}$ & & $\begin{array}{l}-0.1466 \\
(0.0986)\end{array}$ & \\
\hline İşletme dışı yatırım & $\begin{array}{l}-0.9478 \\
(0.4262) \\
\end{array}$ & $* *$ & $\begin{array}{l}-0.1820 \\
(0.0790)\end{array}$ & $* *$ \\
\hline $\begin{array}{l}\text { Köye yenilikleri getirme (önder çiftçi, muhtar:1, } \\
\text { Diğer:0) }\end{array}$ & \begin{tabular}{|l|l}
0.3154 \\
$(0.4048)$
\end{tabular} & & $\begin{array}{l}0.0577 \\
(0.0758) \\
\end{array}$ & \\
\hline $\begin{array}{l}\text { Tarım sigortalarının kapsamının } \\
\text { genişletilmesini isteme }\end{array}$ & $\begin{array}{l}0.8087 \\
(0.4888)\end{array}$ & * & $\begin{array}{l}0.1363 \\
(0.0750)\end{array}$ & * \\
\hline
\end{tabular}

Standart hata değerleri parantez içerisinde gösterilmiştir.

$* * *, * *, *$ surasılla $0.01,0.05$ ve 0.10 ihtimal düzeyinde istatistiki anlamlılığ göstermektedir.

Bitkisel ürün sigortası yaptırma ile çiftçinin eğitimi arasında pozitif yönlü bir ilişki mevcuttur. Çiftçinin eğitim düzeyi arttıkça bitkisel ürün sigortası yaptırması \%8.11 artmaktadır. Bu durum istatistiki açıdan önemlidir $(\mathrm{P} \leq 0.10)$ (Çizelge 3 ). Eğitim seviyesi ile sigorta yaptırma isteği arasında pozitif yönlü ilişki Kuzey Avrupa (LiesivaaraandMyyra, 2014) ile Kırklareli ve Edirne illerinde (Aydın ve ark., 2016) yapılan çalışmalarda da tespit edilmiştir.

Bitkisel ürün sigortası yaptırma ile bitkisel üretimden elde edilen gelir arasında pozitif yönlü bir ilişki mevcuttur. Çiftçinin bitkisel üretimden elde ettiği gelir 1000 TL arttığında bitkisel ürün sigortası yaptırması \%0.39 artmaktadır. Bu durum istatistiki açıdan önemlidir $(\mathrm{P} \leq 0.01)$. Bitkisel üretimden elde edilen gelir sigorta primlerinin ödenmesinde büyük önem taşımaktadır (Çizelge 3).

Bitkisel ürün sigortası yaptırma ile çiftçinin işletme dışı yatırımı olması arasında negatif yönlü bir ilişki mevcuttur. Çiftçinin tarımsal işletme dışı yatırımı olması durumunda bitkisel ürün sigortası yaptırması \%18.20 azalmaktadır. Bu durum istatistiki açıdan önemlidir ( $\mathrm{P} \leq 0.05)$ (Çizelge 3). Çin'de (Body ve ark., 2011) ve Pakistan'da (Ullah ve ark., 2015) yapılan çalışmalarda da benzer sonuçlar elde edilmiştir.

Bitkisel ürün sigortası yaptırma ile çiftçinin tarım sigortalarının kapsamının genişletilmesini istemesi arasında pozitif yönlü bir ilişki mevcuttur. Tarım sigortalarının kapsamının genişletilmesini isteyen çiftçilerin diğerlerine göre bitkisel ürün sigortası yaptırma durumu \%13.63 artmaktadir. Bu durum istatistiki açıdan önemlidir $(\mathrm{P} \leq 0.10)$ (Çizelge 3$)$.

\section{SONUÇ ve ÖNERILLER}

$\mathrm{Bu}$ çalışmada çiftçilerin bitkisel ürün sigortası yaptırmalarını etkileyen çiftçi ve işletme özellikleri Binomial Probit modeli ile analiz edilmiştir. Analiz sonucunda çiftçilerin bitkisel üretim tecrübesi, ailedeki birey sayısı, çiftçinin eğitimi, bitkisel üretim geliri ve bitkisel ürün sigortaları kapsamının genişletilmesi isteği arasında pozitif yönlü, işletme dışı yatırımla ise negatif yönlü ilişki olduğu tespit edilmiştir.

Araştırma bölgesinde ailedeki birey sayısının yaklaşık yarısı tarımsal üretimle uğraşmaktadır. Tarımla uğraşan bireylerin işletmelerinde kalması, tarımsal üretime devam etmesi ve kırsal alandan kente göçün önlenmesi açısından çiftçilerin gelir dalgalanmalarının en aza indirilmesi büyük önem taşımaktadır. $\mathrm{Bu}$ nedenle sadece bitkisel ürün sigortası değil büyükbaş ve küçükbaş hayvan hayat sigortalarının da yaygınlaştırılması gerekmektedir. Ayrıca bitkisel ürün sigortası yaptırmayanların sigorta yaptırmama ve sigorta yaptıranların tekrar sigorta yaptırmama nedenleri araştırılmalıdır. Bu araştırmaların sonuçlarına göre yeni politikalar oluşturulmalıdır.

Bitkisel ürün sigortası yaptıran, bitkisel üretimden elde ettikleri geliri yüksek, eğitimli ve deneyimli çiftçilerin deneyimlerinden faydalanılarak sigorta yaptırmayan çiftçilerin sigorta yaptırması 
sağlanabilir.

Araştırma bölgesi Meteoroloji Genel Müdürlüğü'nün verilerine göre hafif, orta ve şiddetli kuraklığın görüldüğü bölgedir. Bölgede yoğun olarak karşılaşılan risk (\%49.47) olan kuraklık, sadece buğday değil tüm ürünler için sigorta kapsamına alınmalıdır. $\mathrm{Bu}$ durumda ürün verim ve kalitesini olumsuz yönde etkileyen kuraklık riski, çiftçiler tarafından transfer edebilecektir.

Sonuç olarak, Konya ili Ilgın ilçesinde çiftçilerin büyük bir bölümünün bitkisel ürün sigortasını benimsedikleri tespit edilmiştir. Bitkisel ürün sigortasını benimsemeyen çiftçiler için grup ya da kitle yayım araçları kullanılarak tarım sigortalarının faydaları, prim miktarları, hasar karşısında izleyecekleri yol, tazminat hesabı gibi konularda bilgi verilebilir.

\section{KAYNAKLAR}

Akçaöz H, Özkan B, Kızılay H 2006. Antalya İlinde Tarımsal Üretimde Risk Yönetimi ve Tarım Sigortası Uygulamaları. Tekirdağ Ziraat Fakültesi Dergisi, 3(2): 93-103.

Akkaya Ş, Pazarlığlu MV 1998. Ekonometri II. İkinci Baskı, İstanbul.

Aydın B, Özkan E, Hurma H, Yılmaz F 2016. Kırklareli ve Edirne illerinde üreticilerin ürün sigortası uygulamalarına yaklaşımı. Derim, 33(2): 249-262.

Binici T, Koç AA, Zulauf CR, Bayaner A 2003. Risk Attitudes of Farmers in Terms of Risk Aversion: A Case Study of Lower Seyhan PlainFarmers in Adana Province, Turkey. Turkish Journal of Agriculture\&Forestry, 27(5): 305-312.

Body M, Pai J, Zhang Q, Wan, H,Wang K 2011. Factors Affecting Crop Insurance, Purchases in China: The Inner Monggolia Region. China Agricultural Economic Review, 3(4): 441-450.

Çukur F, Saner G 2008. Malatya İli Kayısı Üretiminde Riskin Ölçülmesi ve Riske Karşı Oluşturulabilecek Stratejiler. Ege Üniversitesi Ziraat Fakültesi Dergisi, 46 (1): 33-42.

Farzaneh, M, Allahyari MS, Damalas CA, Seidavi A 2017. CropInsurance as a Risk Management Tool in Agriculture: The Case of Silk Farmer in Nothern Iran. Land UsePolicy, 64: 225-232.

Ghazanfar S, Qi Wen Z, Abdullah M, Ahmad J, Khan I 2015. Farmers' Willingness To Pay For Crop Insurance In Pakistan. Journal of Business, Economics and Finance, 4(2): 166-179.

Gujarati DN 2006.Basic Econometrics. Third Edition, Mc Graw-Hill,USA.

Hassanpour A, Pasha M, Susana L, Rahmanian N, Santomaso AC,Ghadiri M 2013. Analaysis of Seeded Granulation in High Shear Granulators by Discrete Element Method, Powder Technol. 238:5055 .
İkikat Tümer E 2004. Erzurum Merkez İçe Köylerindeki Çiftçilerin Tarım Sigortası İle İlgili Eğilimleri Üzerine Bir Araştırma, Atatürk Üniversitesi Fen Bilimleri Enstitüsü, Tarım Ekonomisi Ana Bilim Dalı (Yüksek Lisans Tezi), 57 Sayfa, Erzurum.

İkikat Tümer E2011a. Bitkisel Ürün Sigortası Yaptırma İsteğinin Belirlenmesi: Tokat İli Örneği. Atatürk Üniversitesi Ziraat Fakültesi Dergisi, 42 (2): 153-157.

İkikat Tümer E 2011b. Erzurum, Erzincan ve Bayburt İllerinde (TRA I Bölgesi) Çiftçilerin Riske Karşı Tutumları ve Olası Sigorta Primlerinin Belirlenmesi Üzerine Bir Araştırma. Atatürk Üniversitesi Fen Bilimleri Enstitüsü, Tarım Ekonomisi Ana Bilim Dalı,(Doktora Tezi), 233 Sayfa, Erzurum.

Karahan Uysal Ö, Saner G, Engürülü B, Naseri Z 2014. Dünyada ve Türkiye'de Tarım Sigortalarındaki Gelişmelerin Düşündürdükleri, 11. Tarım Ekonomisi Kongresi, 3-5 Eylül 2014, Cilt 2: 1042-1050, Samsun.

Liesivaara P, Myyra S 2014. Willingnessto Pay for Agricultural Crop Insurance in the Northern EU. Agricultural Finance Review, 74(4): 539-554.

Miran B 2013. Temel İstatistik, Ege Üniversitesi Basımevi, İzmir.

Naseri Z, Saner G 2017. Uşak İlinde Buğday Üreticilerinin Olası Kuraklı Sigortasını Benimsemesinde Etkili Olan Faktörlerin Analizi. Balkan ve Yakındoğu Sosyal Bilimler Dergisi, 03 (02): 169-180.

Saner G 1999. Tarımda Riskin Ölçülmesine İlişkin Bir Deneme "Süt Siğırcılığı Örneği”, E.Ü. Ziraat Fakültesi Yayınları, ISBN 975-96867-0-8, İzmir.

Sarımeşeli M 2000. Ekonometri El Kitabı. Birinci Baskı, Gazi Kitabevi Ankara.

Sayın B, Çelikyurt MA, Kaya N 2014. Üretici Gözüyle Tarım Sigortaları Uygulamaları: Antalya İli Örneği, XI. Tarım Ekonomisi Kongresi, 3-5 Eylül 2014, cilt 2: 1077-1084 Samsun.

Sherrick BJ, Barry PJ, Ellinger PN, Schnitkey GD 2004. Factors influencing farmers' crop insurance decisions. American Journal of Agricultural Economics, 86(1), 103- 114.

TARSIM 2017. Faaliyet raporu. file:///C:/Users/user/Downloads/2016_faaliyet_rapo ru\%20(2).pdf (Erişim:29.04.2017)

Terin M, Aksoy A 2015. Devlet Destekli Bitkisel Ürün Sigortası Uygulama Sonuçları Üzerine Bir Araştırma: Ortadoğu Anadolu (TRB) Bölgesi Örneği. ÇOMÜ Zir. Fak. Derg 3 (2): 35-43.

Ullah R, Shivakoti GP, Ali G 2015. Factors Effecting Farmers' Risk Attitudeand Risk Perceptions: The Case of Khyber Pakhtunkhwa, Pakistan. International Journal of Disaster Risk Reduction, 13: 151-157.

Xiu F, Xiu F, Bauer S 2012. Farmers' willingness to 
pay for cow insurance in Shaanxi province, China. Procedia Economics and Finance, 1: 431-440.

Yavuz F 2001. Tarım Politikası II: Genel Politikalar ve Uluslar arası Tarım Ticareti Ders Notları. Atatürk Üniv. Ziraat Fak. Ders Yayınları No:186, Erzurum,
25-30 s.

Zulfiqar F, Ullah R, Abid M, Hussain, A 2016. Cotton Production Under Risk: A Simultaneous Adoption of Risk Coping Tools. Natural Hazards, 84(2): 959974. 